\title{
Towards the low temperature growth of uniform diameter multi walled carbon nanotubes by catalytic chemical vapour deposition technique
}

\section{Thirunavukkarasu Somanathan ${ }^{1, *}$ and Arumugam Pandurangan ${ }^{1,2}$}

Mesoporous MCM-41 molecular sieves containing f-block transition elements (gadolinium) with various Si/Gd ratios $(50,75$ and 100) were synthesised by a hydrothermal method. Their mesoporous structure was confirmed by $\mathrm{X}$-ray diffraction, nitrogen sorption studies, thermogravimetric analysis, scanning and transmission electron microscopy. The local environment of Gd in the material was studied by electron paramagnetic resonance. The compatibility of the catalyst for the synthesis of uniform diameter CNTs by varying the temperature from 400 to $650^{\circ} \mathrm{C}$ with fixed flow rates of $\mathrm{N}_{2}$ and $\mathrm{C}_{2} \mathrm{H}_{2}(140 \mathrm{ml} / \mathrm{min}$ and $40 \mathrm{ml} / \mathrm{min}$, respectively). The product is mostly metal containing thin MWCNTs with diameter of 10 20 nm. Characterisation shows that a combination of Gd-MCM-41 (100) catalyst gives a high yield of high quality MWCNTs under optimum growth conditions.

Keywords: MWCNTs; Gd carbon nanotubes; Contrasting agents; Magnetic resonance imaging

Citation: Thirunavukkarasu Somanathan and Arumugam Pandurangan, "Towards the low temperature growth of uniform diameter multi walled carbon nanotubes by catalytic chemical vapour deposition technique", Nano-Micro Lett. 2, 204-212 (2010). doi:10.5101/nml.v2i3.p204-212

Carbon nanotubes (CNTs) are attractive materials for applications in future LSI interconnects because of their excellent electrical, thermal and mechanical properties. Recently, the electrical properties of multiwalled CNT bundles grown by chemical vapor deposition (CVD) have been intensively investigated for interconnect applications [1-4]. Lowtemperature growth of CNTs is one of the most fundamental issues to be resolved for development of CNT based on interconnects technology compatible with LSI manufacturing processes.

Generally, carbon nanotubes have been synthesized by three different techniques: arc discharge between two graphite electrodes [5], laser evaporation of carbon target [6] and chemical vapour deposition (CVD) [7]. The major drawback of arc discharge and laser evaporation methods is that they are extremely uncontrolled in terms of process parameters, resulting in CNTs that contains significant fractions of unwanted material and that are difficult to manipulate and assemble in specific designs. CVD method is based on the thermal decomposition of hydrocarbon compounds over transition metal catalyst particles. It appears to be a simple and economic technique to synthesize this kind of material at a low temperature, ambient pressure and it represents the best hope for large scale production.

To date, all the metal-catalyzed CNT growth studies have mainly focused on transition metals. Curiously, f-block transition elements also referred to as inner transition elements have still not been well explored. One reason could be that inner transition elements are not known to be highly catalytic as the transition elements. It has also been suggested that lanthanoids such as gadolinium and europium exhibit insufficient carbon solubility, slow carbon diffusion, and limited carbide formation to catalyze CNT growth [8]. Recently, gadolinium and europium were used 
as catalyzed to synthesize single walled carbon nanotubes [9]. Gd (III) ion exchanged $\mathrm{NaY}$ zeolite has been reported as a gastrointestinal contrast agent [10]. However, Y zeolite has a pore size of around $1.3 \mathrm{~nm}$ and the small pores hinder the water movements. Also, the extra-framework metal ion is held inside the channel mainly by Coulomb interaction, hence it is prone to leaching and the toxic gadolinium hydroxide would form and precipitate out under physiological conditions. In general, MCM-41 of the M41S family are materials of interest because of their remarkable properties such as high surface, large pore volume and narrow pore size distribution and the ease with which their surface can be functionalized [11]. Mesoporous silica would be an excellent carrier for the metal and as it is porous: water can freely move in and out of the frame, yet the rigidity of the frame would impede the rotational movement of the metal and improve the relaxation of water. Nanosized silica with size of less than $100 \mathrm{~nm}$ is small enough to pass through the body, and also is able to enter cells. Nanosized porous silica, as a container, can deliver drugs with gate control to cells [12] with MRI capability one can thus have a very powerful imaging and drug delivery system.

Hence, in this present work, for the first time we used gadolinium metal support with MCM-41 as a sacrificing template for the synthesis of high quality and uniform diameter of multiwalled carbon nanotubes by low temperature CVD process. The formation of highly graphitized MWCNTs with metal particles was confirmed by XRD, TGA, SEM, TEM, HRTEM and Raman spectroscopy.

\section{Experimental Methods}

\section{Synthesis of Gd-MCM-41 molecular Sieves}

Gd-MCM-41 with various ratios $(\mathrm{Si} / \mathrm{Gd}=50,75$, and 100$)$ were synthesized hydrothermally according to our previous report $[13,14]$ using a gel composition of $1: X: 0.2: 0.89: 120$ $\mathrm{SiO}_{2}: \mathrm{Gd}\left(\mathrm{NO}_{3}\right)_{2}: \mathrm{CTAB}: \mathrm{H}_{2} \mathrm{SO}_{4}: \mathrm{H}_{2} \mathrm{O}$. Sodiummetasilicate and gadolinium nitrate are used as the source for silicon and gadolinium respectively, whereas cetyltrimethyl ammonium bromide (CTAB) and sulphuric acid were used as structure directing template and $\mathrm{pH}$ adjuster respectively.

\section{Synthesis of carbon nanotubes}

Experiments to produce CNTs were carried out in a horizontal furnace at atmospheric pressure. About $100 \mathrm{mg}$ of the catalyst was spread on a long quartz boat, which was placed inside a quartz tube. The reaction mixture containing acetylene and nitrogen gas was passed over the catalyst bed for a predetermined time. The experiments were carried out at different reaction temperatures: $450,500,550$ and $600^{\circ} \mathrm{C}$. The catalyst was then activated by passing nitrogen gas ( $99.9 \%$ purity) for $30 \mathrm{~min}$ at a flow rate of $140 \mathrm{ml} / \mathrm{min}$. Acetylene gas $(99.99 \%$ purity) was then passed at a rate of $40 \mathrm{ml} / \mathrm{min}$ for $10 \mathrm{~min}$ through the reaction chamber, while the nitrogen gas flow rate was maintained at $140 \mathrm{ml} / \mathrm{min}$. Prior to collecting samples from the tubes, the furnace was cooled down to room temperature by maintaining a nitrogen flow. The sample was collected as black powder from the quartz boat.

\section{Characterization of Catalysts and Carbon nanotubes}

The powder XRD diffraction patterns for the calcined mesoporous Gd-MCM-41 molecular sieves with various ratios were obtained with a stereoscan diffractometer using nickel-filtered $\mathrm{Cu} \mathrm{K} \alpha$ radiation $(\lambda=0.15418 \mathrm{~nm})$ and a liquid nitrogen cooled germanium solid-state detector. Surface area, pore volume and pore size distribution were measured by nitrogen adsorption at $-196^{\circ} \mathrm{C}$ with an ASAP-2010 porosimeter from micromeritics corporation (Norcross, GA). The samples were degassed at $350^{\circ} \mathrm{C}$ at $10^{-5}$ mbar overnight prior to the adsorption experiments. The mesopore volume was estimated from the amount of nitrogen adsorbed at a relative pressure of 0.99 by assuming that all the mesopores were filled with condensed nitrogen in the normal liquid state. Pore size distribution was estimated using the Barrett, Joyner and Halenda (BJH) algorithm (ASAP-2010 built-in software from micromeritics). The thermal properties of the mesoporous sample Gd-MCM-41 and the purity of CNTs were investigated by thermogravimetric analysis (TGA). The coordination environment of gadolinium were analysed by electron paramagnetic resonance (EPR) spectroscopic technique (Varian E112 Spectrometer operating in the X-band 9.2 GHz frequency) at liquid nitrogen temperature. Scanning electron microscope (JEOL JSM 840) was performed to analyse the morphology and microstructure of catalysts and CNTs, respectively. The growth morphology and crystallinity of the tubular structures were confirmed by transmission electron microscopy (Phillips CM 200, TEM). In addition, FT-Raman spectroscopy (FRA 106 BRUKER) using an excitation wavelength of $1064 \mathrm{~nm}$ of Nd:YAG Laser was also employed to characterized the carbon nanotubes.

\section{Results and discussion}


Physico-chemical characteristics of Gd incorporated MCM-41 materials

The physico-chemical characteristics of the Gd incoporated MCM-41 materials that were used for the synthesis of carbon nanotubes were investigated by means of XRD, $\mathrm{N}_{2}$ sorption studies, TGA, SEM, TEM and EPR analysis.

\section{XRD of the catalysts}

In order to aware about the periodic and porous nature of the materials, the XRD analysis was performed. The XRD patterns of Gd-MCM-41 $(\mathrm{Si} / \mathrm{Gd}=50,75$ and 100$)$ are shown in Fig.1 in which the intense peak between 2.1 to 2.4 (20) due to (100) plane and weak planes between 4 and 5.5 are due to (110) and (200) planes confirmed the hexagonal mesophase of the material which are similar to that of pristine MCM-41 [11]. The XRD patterns of Gd (III) incorporated samples show the hexagonal porous structure and the gradual broadening of peaks decreases and also it reveals that the structure ordering increases as the loading of Gd (III) increases respectively, due to this the pore structure would be well ordered hexagonal pores. This result also provides indirect evidence that Gd (III) is indeed incorporated into the mesoporous silica framework.

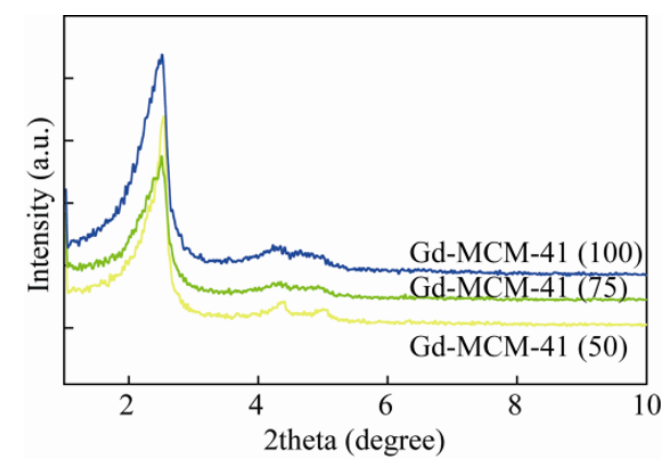

FIG. 1. X-ray diffraction patterns of Gd-MCM-41 catalysts.

\section{$\mathbf{N}_{2}$ sorption studies}

The $\mathrm{N}_{2}$ sorption analysis was employed for Gd-MCM-41 materials and their data are presented in Table 1 . The $\mathrm{N}_{2}$ sorption studies were typical for type IV, with a hysteresis loop characteristic of mesoporous materials (see Fig. 2). The isotherms exhibited three stages. The first stage is due to monolayer adsorption of nitrogen to the walls of the mesopores at a low relative pressure $\left(\mathrm{P} / \mathrm{P}_{0}<0.25\right)$. The second stage is characterized by a steep increase in adsorption $\left(\mathrm{P} / \mathrm{P}_{0}>0.25\right)$. As the relative pressure increases, the isotherm exhibits a sharp inflection characteristic of capillary condensation within the uniform mesopores. The $\mathrm{P} / \mathrm{P}_{0}$ at the inflection is related to the diameter of the mesopore [15] and the steepness of this step indicates the uniformity of pore size distribution. The third stage in the adsorption isotherm is the gradual increase in volume with $\mathrm{P} / \mathrm{P}_{0}$ due to multilayer adsorption on the outer surface of the particles. The isotherms of mesoporous materials with high metal content generally show a strong increase at high pressure, attributed to the condensation of nitrogen within voids formed by crystal aggregates. The samples exhibit isotherms with a well-developed step in the relative pressure $\left(\mathrm{P} / \mathrm{P}_{0}\right)$ range corresponding from 0.25 to 0.45 . A characteristic hysteresis loop observed for sample in the region of $\mathrm{P} / \mathrm{P}_{0}$ above 0.3 is assigned to capillary condensation in the mesopores [16]. It should be noted that, as the metal contents in MCM-41 increase, a sharp inflection step i.e. characteristic of capillary condensation, has been shifting to the higher $\mathrm{P} / \mathrm{P}_{0}$ values lead to increase in pore size. This observation can also be supported by XRD patterns of Gd-MCM-41, where the $d$-spacing values and pore volume are also increased with increase in metal content.

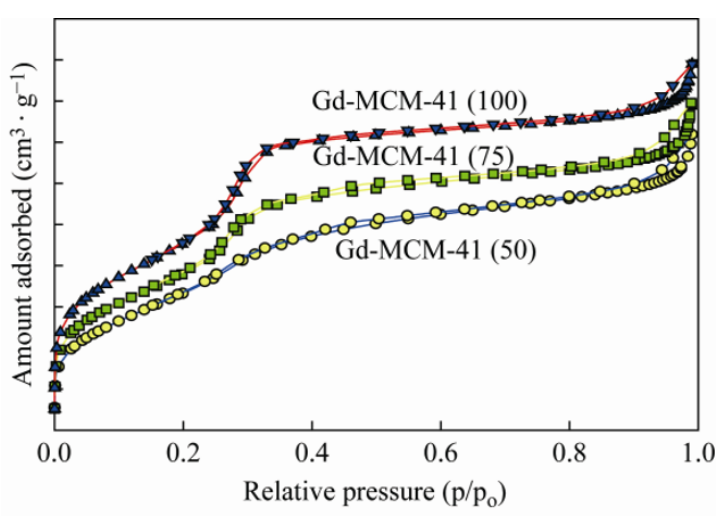

FIG. 2. $\mathrm{N}_{2}$ sorption isotherms of Gd-MCM-41 catalysts.

Table 1. Textural properties of the catalysts.

\begin{tabular}{cccccc}
\hline Catalysts & $\mathrm{d}_{100}(\mathrm{~nm})$ & Unit cell- $\mathrm{a}_{0}(\mathrm{~nm})$ & Surface area $\left(\mathrm{m}^{2} \mathrm{~g}^{-1}\right)$ & Pore size BJH $(\mathrm{nm})$ & Total Pore Volume BJH $\left(\mathrm{cm}^{3} \mathrm{~g}^{-1}\right)$ \\
\hline Gd-MCM-41 (50) & 3.49 & 4.03 & 662 & 3.39 & 0.498 \\
Gd-MCM-41 (75) & 3.51 & 4.12 & 695 & 3.42 & 0.551 \\
Gd-MCM-41 (100) & 3.51 & 4.12 & 810 & 3.43 & 0.587 \\
\hline
\end{tabular}




\section{Thermogravimetric analysis}

The thermal properties of the mesoporous sample Gd-MCM-41 were investigated by TGA. The thermograms of the as-synthesized Gd-MCM-41 (50), Gd-MCM-41 (75) and Gd-MCM-41 (100) catalysts are presented in Fig. 3. The initial weight loss up to $120^{\circ} \mathrm{C}$ is due to desorption of physically adsorbed water and the weight loss from $120^{\circ} \mathrm{C}$ to $350^{\circ} \mathrm{C}$ are attributed to the organic template. The oxidative desorption of the organic template takes place at $180^{\circ} \mathrm{C}$ and the minute quantity of weight loss above $350^{\circ} \mathrm{C}$ to $550^{\circ} \mathrm{C}$ is related to water loss from the condensation of adjacent $\mathrm{Si}-\mathrm{OH}$ groups to form siloxane bond $[11,17]$.

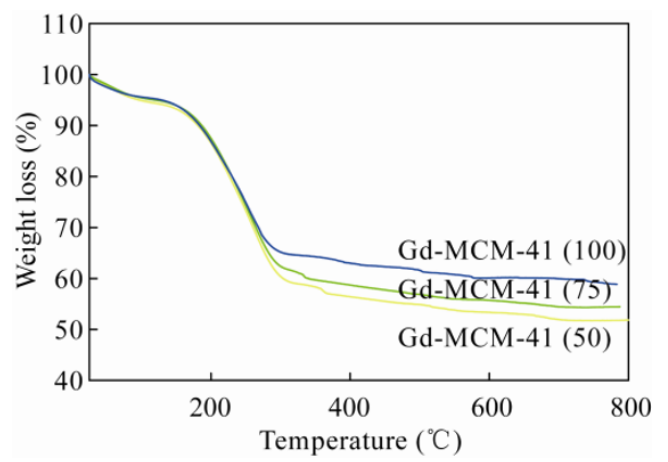

FIG. 3. TGA of the Gd-MCM-41 catalysts.

\section{SEM and TEM analysis for the catalyst}

The particle size and morphology of Gd-MCM-41 (100) sample was determined by SEM analysis and shown in Fig. 4. The formation of various periodic mesoporous materials starts with nucleation, which involves the surfactant-silicate interactions, and these interactions facilitate the assembly of the

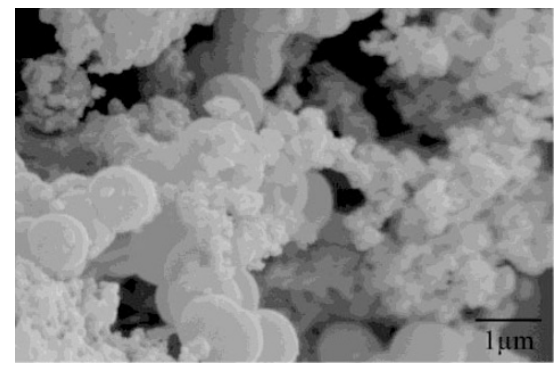

FIG. 4. SEM image of Gd-MCM-41 (100) catalyst.

surfactant-silicate species in the desired morphology. However, the presence of foreign ions in the synthesis gel alters the structure directing action of the template and the attenuations further depend on the nature of metal source used. In accordance with this, the micrographs show marked differences in the structure of the MCM-41 surface after the metal incorporation
[18]. The size and morphology of Gd-MCM-41 (100) catalysts were investigated with TEM are presented in Fig. 5. The TEM picture of MCM-41 exhibits an image with strong contrast dark lines indicative of the regular crystal lattice of MCM-41 in the hexagonal array an ordered mesopore structure.

\section{EPR analysis}

Gadolinium (III) ions are often used in paramagnetic complexes due to their good paramagnetism. The EPR spectrum with three and more absorption signals is usually assigned to isolated $\mathrm{Gd}^{3+}$ ions, while a single broad absorption signal encompassing $g=2$ is assigned to the group of $\mathrm{Gd}^{3+}$ ions [19]. After crystallization the EPR spectra mainly consist of relative large line with $\mathrm{g}=2.0$ suggesting that the surrounding of $\mathrm{Gd}^{3+}$ ions are experiencing weak crystal fields resulting from structural relaxation [20] which is shown in Fig. 6.

\section{The role of reactor temperature during growth}

An important parameter, which greatly affects the microstructure and the yield of CNTs, for the activity of catalytic metals and the decomposition of carbon source are both, correlated with the growth temperature. In this section, we have preferred low metal content catalyst Gd-MCM-41 (100) to study the influence of reaction temperatures ranging from 400 to $650^{\circ} \mathrm{C}$. Figure 7 depicts the percentage yield of CNTs as a

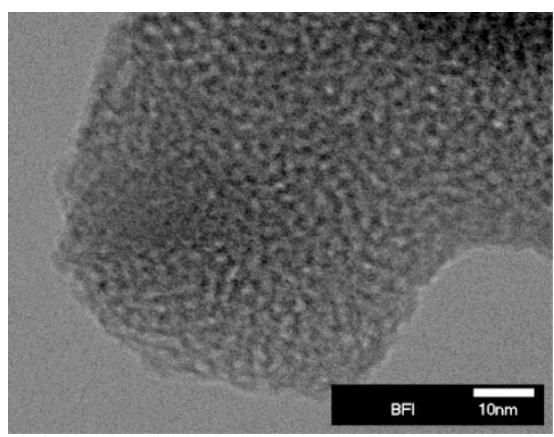

FIG. 5. TEM image of Gd-MCM-41 (100) catalyst.

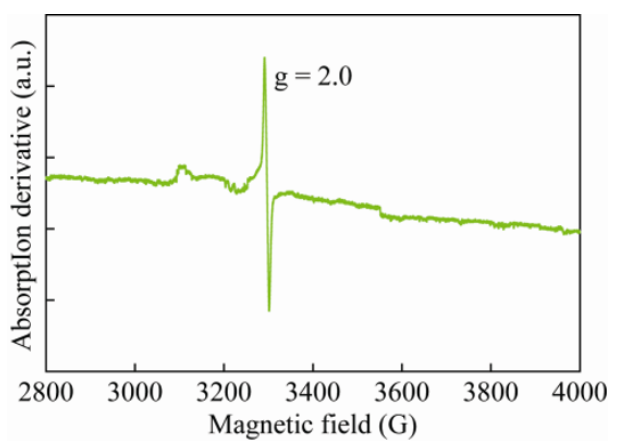

FIG. 6. EPR spectrum of Gd-MCM-41 (100) catalyst. 
function of growth temperature. A poor yield (65.06 \%) was obtained for temperature at $400^{\circ} \mathrm{C}$, possibly due to slow catalytic decomposition of $\mathrm{C}_{2} \mathrm{H}_{2}$, while CNTs growth became significant at $450^{\circ} \mathrm{C}$. The low yield of CNTs $(72.15 \%)$ at $450^{\circ} \mathrm{C}$ may be related to non uniformity from the catalyst or defect formation in the graphite sheets at lower temperature. The incomplete crystallization of the graphite sheet results in a rough surface and curved shape of the nanotubes. It can be seen in Fig. 7, at the temperature of $550^{\circ} \mathrm{C}$, the yield of CNTs on Gd-MCM-41 (100) catalyst is $89.25 \%$. It is generally accepted that CNTs are formed by carbon atom dissolution, diffusion and precipitation through the catalyst in the CVD process [21]. The dissolution, diffusion and precipitation of the carbon atoms are affected by temperature as well as by the carbon concentration.

When the deposition temperature is higher than $550^{\circ} \mathrm{C}$, the yield of CNTs is decreased up to $68.45 \%$. At higher temperature, the decomposition of $\mathrm{C}_{2} \mathrm{H}_{2}$ promotes and consequently increases the concentration of carbon atoms, which can result in a dissolution rate that is higher than the rates for diffusion and precipitation. In that case carbon atoms will accumulate on the surface of the catalyst to form a carbon shell [22]. The catalyst particles then lose their activity and it retards the growth of CNTs. Moreover, when the temperature is too high, a chemical reaction may take place between the carbon and the metal, leading to the formation of metal carbide, which is passivity the catalyst and then started dropping at approximately $600^{\circ} \mathrm{C}$. At too high temperatures, the catalyst become highly mobile and quickly agglomerates into metal particles that are too large particles to initiate CNTs nucleation. These sintered large particles are rapidly encapsulated by carbon deposits and become inactive. Hence $550^{\circ} \mathrm{C}$ was found to be optimum low growth temperature to achieve the very high yield and hollow structure of good crystalline MWCNTs which showing the graphitic layers of the tubes.

\section{The role of Gd-MCM-41 catalysts for the growth of MWCNTs}

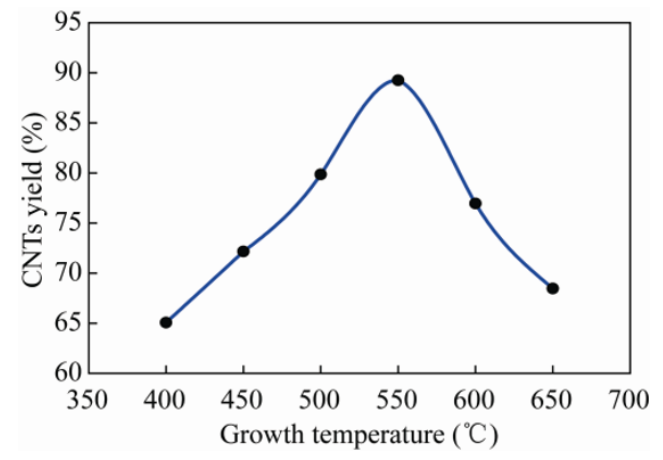

FIG. 7. Percentage of CNTs yield with various temperatures.

The growth of CNTs was done using Gd-MCM-41 with different $\mathrm{Si} / \mathrm{Gd}$ ratios $\left(50,75\right.$ and 100) with $\mathrm{N}_{2}$ and $\mathrm{C}_{2} \mathrm{H}_{2}$ flow rate of $140 \mathrm{ml} / \mathrm{min}$ and $40 \mathrm{ml} / \mathrm{min}$, respectively were purged inside the tubular furnace for $10 \mathrm{~min}$ at optimized temperature of $550^{\circ} \mathrm{C}$. The results are given in Table 2 . The activity of the catalysts followed the order Gd-MCM-41 (100) > Gd-MCM-41 (75) $>$ Gd-MCM-41 (50). High carbon yield was observed over Gd-MCM-41 (100) of about $78.70 \%$ than other $\mathrm{Si} / \mathrm{Gd}$ ratios, where the yield of $\mathrm{Si} / \mathrm{Gd}=50$ and 75 were 62.78 and $68.09 \%$, respectively which may be ascribed to its greater ability to decompose unsaturated hydrocarbons. If the metal catalyst is exposed to acetylene, metal particles can easily diffuse on the surface to form larger particles, leading to MWCNT growth. The percentage of carbon yield for above mention catalysts are presented in Table 2, it can be clearly understood that support plays a prominent role in determining the dispersion and hence the catalytic activity of the metals in the production of CNTs.

Though $\mathrm{Gd}^{3+}$ ion is toxic and when it is sequestered by chelation or encapsulation with another material, it reduced is toxicity therefore we utilized nanosized mesoporous siliceous material as a chelating agent in order to reduce the toxicity of gadolinium ion. Since, in our present study, we have used porous silica material to reduce the toxicity of metal and it would be an excellent carrier for the metal because of its porous nature. Furthermore, carbon nanotubes with gadolinium have access to water molecules because of active centers (for $\mathrm{Gd}^{3+}-\mathrm{OH}_{2}$

Table 2. Influence of the catalysts

\begin{tabular}{cccc}
\hline Catalysts & Reaction temperature $\left({ }^{\circ} \mathrm{C}\right)$ & Flow rate & Acetylene (ml/min) \\
\cline { 3 - 4 } Gd-MCM-41 (50) & & Nitrogen $(\mathrm{ml} / \mathrm{min})$ & 62.78 \\
Gd-MCM-41 (75) & 550 & 140 & 40 \\
Gd-MCM-41 (100) & & & 68.09 \\
\hline
\end{tabular}


bonding), since carbon nanotubes are known to be good transporters of water [23] and protons [24], whereas the active centers in gadofullerenes do not have this access. From a practical point of view, the rate of proton exchange is especially important since it contributes to the proton relativity [25]. These gadolinium carbon nanotubes are the contrast agent materials where superparamagnetic metal centers have access to many coordinated or exchanging water molecules per $\mathrm{Gd}^{3+}$ ion. These $\mathrm{Gd}^{3+}$ nanotubes species are linear superparamagnetic molecular magnets with MRI efficacies are more than any $\mathrm{Gd}^{3+}$ based contrast agent in future clinical use.

\section{Characterization of carbon nanotubes}

\section{XRD}

Figure 8 shows the XRD pattern of $\mathrm{Gd}$ containing MWCNTs synthesized at temperature of $550^{\circ} \mathrm{C}$. The highest sharp peak at $2 \theta=25.8^{\circ}$ can be assigned to graphite (002),

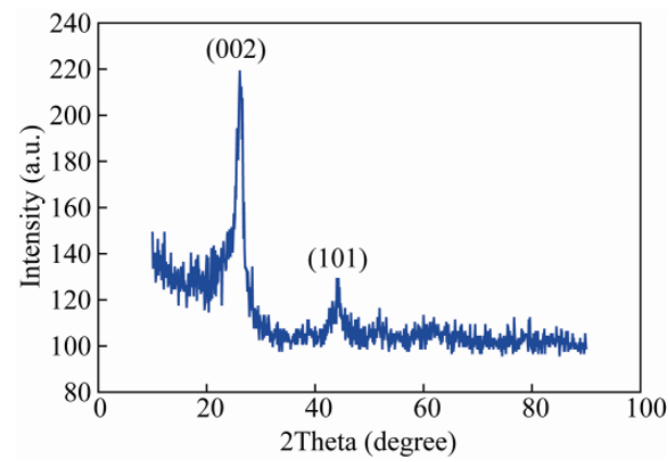

FIG. 8. XRD pattern of Gd containing MWNTs at $550^{\circ} \mathrm{C}$.

indicating that graphite layers are regularly stacked. While the other peaks at $44.3^{\circ}(101)$ correspond to the remaining graphitic particles, a similar trend was observed by previous reporters [26].

\section{TGA}

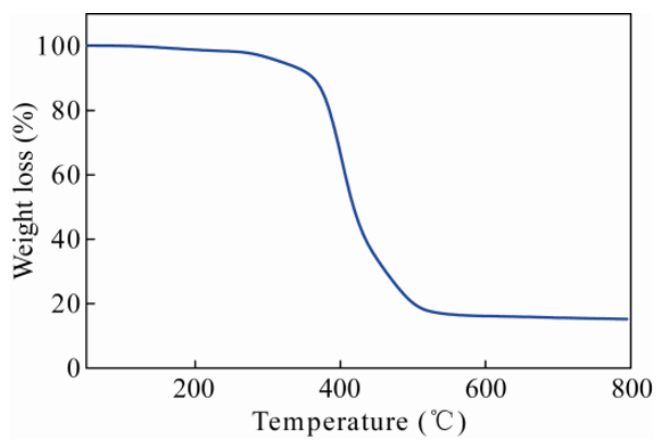

FIG. 9. TGA of MWNTs in air at $550^{\circ} \mathrm{C}$.
Figure 9 shows the synthesized MWCNTs characterized by TGA in air. The weight loss is due to the combustion of carbon with oxygen and therefore, corresponds to the carbon content in the sample. The major mass loss observed in the temperature range of $375 \sim 585^{\circ} \mathrm{C}$ due to the oxidation of carbon nanotubes, which is consistent with previous report [27].

\section{SEM and TEM analysis}

SEM image of CNTs prepared by Gd-MCM-41 (100) catalyst with an optimized condition of flow rate of acetylene and temperature were $40 \mathrm{ml} / \mathrm{min}$ and $550^{\circ} \mathrm{C}$ respectively, is shown in Fig. 10. The image clearly shows thinner nanotubes with metal particles at the tip of the tubes, and it also in agreement with TEM observations.

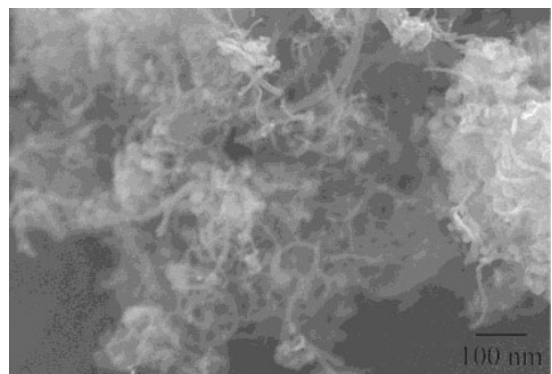

FIG. 10. SEM image of CNTs using Gd-MCM-41 (100) catalyst.
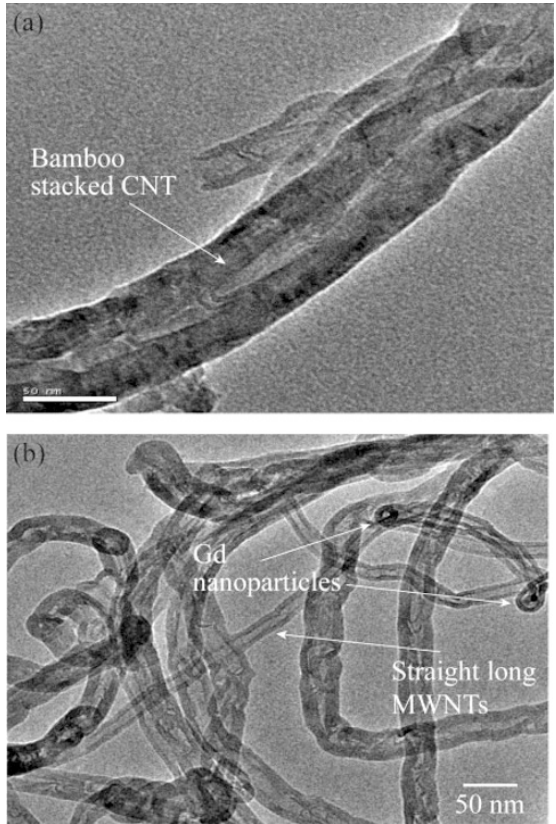

FIG. 11. TEM image of bamboo shaped Gd containing MWNTs at $550^{\circ} \mathrm{C}$.

The TEM image (see Fig. 11a) indicates that CNTs grown are multiwalled and bamboo shaped. The structure shows that the CNTs grow with layers of graphite deposited on the surface of Gd catalyst were separated from the catalyst surface resulting in the growth of CNT with closed end (see Fig. 11b). However, if the deposition on Gd catalyst is too fast due to higher 
decomposition rate of $\mathrm{C}_{2} \mathrm{H}_{2}$, the catalyst surface would be encapsulated by the deposits, which prevent the evolution of CNTs. In this condition, the passivation of the catalyst can occur in a catastrophic manner. Therefore, one of the requirements for the CNTs growth is that the decomposition kinetics of $\mathrm{C}_{2} \mathrm{H}_{2}$ should be controlled to supply carbon for nanotube growth without passivation of the catalyst surface. The present work shows that the flow rate of the reaction gas and the reaction temperature are the effective process parameters to control the decomposition kinetics. A reaction temperature of $550^{\circ} \mathrm{C}$ with 10 min duration and a precursor flow rate of $40 \mathrm{ml} / \mathrm{min}$ appear to constitute the optimal conditions for CNTs growth in Gd-MCM-41 catalysts, since they produce a high yield with uniform size of MWCNTs.

To the best of our knowledge, growth mechanism of bamboo like MWCNTs is not entirely clear so far. Many authors proposed the possible mechanism on the basis of their experimental results. Smith et al [28] put forward that bamboo morphology in CNTs may be the result of subtle changes in the growth conditions near the seed metal. Wu et al [29] pointed out that formed nanoparticles lead to growth of bamboo like CNTs; Zhao et al [30] suggested that the difference between the carbon surface and bulk diffusion in the catalyst causes the periodic compartment structures in the bamboo shaped CNTs. In this study, it can be seen that catalyst particles were encapsulated on closed end bamboo like MWCNTs in Fig. 11b. These observations suggest that the growth mode of bamboo like MWCNTs over Gd-MCM-41 (100) catalyst may be consistent with the tip growth mode [31]. Moreover, Gd catalyst nanoparticles tend to form large metallic clusters to form MWCNTs. Also, nonuniformity of diffusion and deposition of carbon on Gd catalyst particles possibility exists according to the tip growth mechanism. These factors may be the causes of bamboo like MWCNTs. Figure 12 presents the HRTEM image of as grown MWCNTs. From this Figure, it is revealed that the diameter of the central hollow portion of MWCNTs is about 10 20 $\mathrm{nm}$. The graphite layer lattice fringes are parallel to the

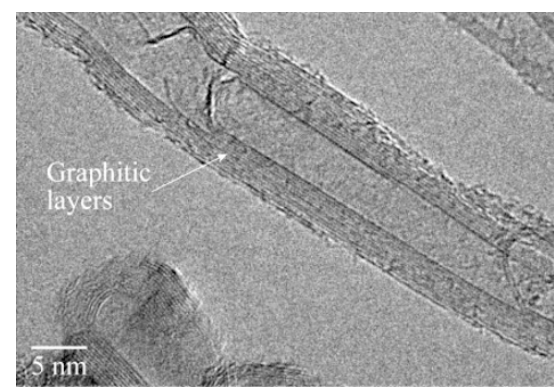

tube axis and also the multiple graphitic walls of the CNTs are clearly visible in this image (see Fig. 12). It should be beneficial for further investigating of the unique structures, properties and applications of gadolinium produce MWNTs.

\section{Raman spectroscopy}

Raman Spectroscopy is an important tool for investigating CNTs, which provides information about the crystalline nature of the sample. Figure 13 shows the Raman spectrum of the sample obtained by Gd-MCM-41 (100) at the optimized temperature and flow rate of acetylene are $550^{\circ} \mathrm{C}$ and $40 \mathrm{~mL} / \mathrm{min}$ respectively. The Raman band emerging in low wavenumbers region of $100 \sim 400 \mathrm{~cm}^{-1}$ are characteristic of low frequency region of SWCNTs, which can distinguish between SWCNTs and

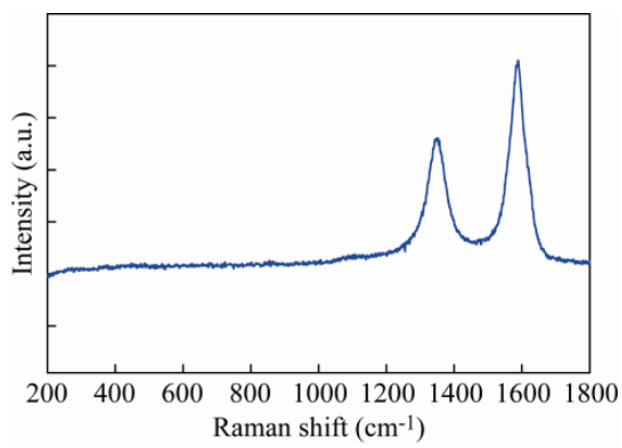

FIG. 13. Raman spectrum of CNTs.

MWCNTs [32]. Additionally, no Raman band appearing in the low wavenumber region below $400 \mathrm{~cm}^{-1}$ is observed. Only two Raman bands emerging in the high wavenumber region are accordance with the characteristic band of the Raman spectra of MWCNTs, further, certifying that the CNTs synthesized in this contribution are multi-wall carbon nanotubes. In the first order Raman scattering region $\left(0 \sim 2000 \mathrm{~cm}^{-1}\right)$, two intense peaks are observed at 1347 and $1595 \mathrm{~cm}^{-1}$, which are referred to as D- and G-bands, respectively. The G-band corresponds to the tangential stretching high frequency $\mathrm{E}_{2 \mathrm{~g}}$ mode of highly oriented pyrolytic graphite (HOPG) and indicates the presence of crystalline graphitic carbon in the CNTs, while the D-band originates from disorder in the $\mathrm{sp}^{2}$ hybridized carbon atoms, characteristics for lattice distortions in the curved graphene sheets or tube ends. Furthermore, pyrolytic carbon particles deposited on nanotubes also contributed to the D-band intensity $[33,34]$. In the present system, $\mathrm{G}$ band is at higher intensity, indicating that the CNTs are graphitized, which is in agreement with the result of TEM observation.

FIG. 12. HRTEM image of MWNTs grown over Gd-MCM-41 (100) catalyst. 


\section{Conclusions}

CNTs possess many desirable qualities that play a central role in the field of nanotechnology. Of the three main techniques for CNT synthesis, CVD based methods are suitable because of their scalability and product purity. The growth of MWCNTs over Gd-MCM-41 catalyst by CVD under atmospheric pressure using acetylene as carbon source at low temperature $\left(550^{\circ} \mathrm{C}\right)$ has been demonstrated. The obtained MWCNTs showed dominant bamboo like morphology. The morphologies, graphitization degree and microstructures of the products were systematically studied. The results show that the combination of Gd-MCM-41 (100) catalyst exhibits highly selective and high yield of uniform diameter of MWCNTs under optimized conditions that too at low reaction time (10min). The TEM image which clearly illustrates that CNTs formed are free from amorphous carbon and also confirms the Gd particles present at the tip of the tube. The graphite layer lattice fringes are parallel to the tube axis and also the multiple graphitic walls of the CNTs are clearly visible in HRTEM. The gadolinium incorporated with nanosized mesoporous silica was found to be stable under reaction conditions, allowing slow reduction and nucleation of metallic clusters for highly selective MWCNTs. This study suggested that the mesoporous molecular sieves could be a promising catalytic template for high yield synthesis of CNTs. As a result, in the near future, the researchers hope to use existing methods of attaching disease-specific antibodies and peptides to gadolinium nanotubes so they can be targeted to cancerous tumors and other diseased cells.

One of the authors, T. Somanathan is thankful to CSIR, New Delhi for the award of Senior Research Fellowship.

Received 17 September; accepted 11 October; published online 22 October 2010.

\section{References}

1. J. C. Coiffic, M. Fayolle, S. Maitrejean, L. E. F. Foa Torres and H. Le Poche, Appl. Phys. Lett. 91, 252107 (2007). doi:10.1063/1.2826274

2. A. Kawabata, S. Sato, T. Nozue, T. Hyakushima, M. Norimatsu, M. Mishima, T. Murakami, D. Kondo, K. Asano, M. Ohfuti, H. Kawarada, T. Sakai, M. Nihei and Y. Awano, Proc. IEEE Int. Interconnect Tech. Conf. 2008, p. 237.
3. D. Yokoyama, T. Iwasaki, K. Ishimaru, S. Sato, T. Hyakushima, M. Nihei, Y. Awano and H. Kawarada, Jpn. J. Appl. Phys. 47, 1985 (2008). doi:10.1143/JJAP.47.1985

4. M. Katagiri, N. Sakuma, M. Suzuki, T. Sakai, S. Sato, T. Hyakushima, M. Nihei and Y. Awano, Jpn. J. Appl. Phys. 47, 2024 (2008). doi:10.1143/JJAP.47.2024

5. T. W. Ebbesen and P. M. Ajayan, Nature 358, 220 (1992). doi:10.1038/358220a0

6. T. Guo, P. Nikolaev, A. Thess, D. T. Colbert and R. E. Smalley, Chem. Phys. Lett. 243, 49 (1993). doi:10. $\underline{1016 / 0009-2614(95) 00825-O}$

7. S. Amelinckx, X. B. Zhang, D. Bernaets, X. Zhang, F. V. Ivanov and J. B. Nagy, Science 265, 635 (1994). doi:10.1126/science.265.5172.635

8. C. P. Deck and K. Vecchio, Carbon 44, 267 (2006). doi:10.1016/j.carbon.2005.07.023

9. M. Swierczewskaa, I. Rusakovab and B. Sitharamana, Carbon 47, 3137 (2009). doi:10.1016/j.carbon.2009. 07.021

10. C. P. Iglesias, L. V. Elst, W. Zhou, R. N. Muller, C. F. G. C. Geraldes, T. Maschmeyer and J. A. Peters, Chem. Eur. J. 8, 5121 (2002). doi:10.1002/1521-3765(20021115)8:22< 5121::AID-CHEM5121>3.0.CO;2-W

11. J. S. Beck, J. C. Vartuli, W. J. Ruth, M. E. Leonowicz, C. T. Kresge, K. D. Schmidt, C. T. W. Chu, D. H. Olson, E. W. Sheppard, S. B. McCullen, J. B. Hggins and J. L. Schlenker, J. Am. Chem. Soc. 114, 10834 (1992). doi: $10.1021 / \mathrm{ja} 00053 \mathrm{a} 020$

12. N. K. Mal, M. Fujiwara and Y. Tanaka, Nature 421, 350 (2003). doi:10.1038/nature01362

13. T. Somanathan, A. Pandurangan and D. Sathiyamoorthy, J. Mol. Catal. A: Chem. 256, 193 (2006). doi:10.1016/ j.molcata.2006.04.052

14. T. Somanathan and A. Pandurangan, J. Porous. Mater. 16, 454 (2009).

15. S. J. Gregg and K. S. W. Sing. Adsorption, Surface Area and Porosity. Academic Press: London 1982.

16. T. R. Pauly, Y. Liu, T. J. Pinnavaia, S. J. L. Billinge and T. P. Rieker, J. Am. Chem. Soc. 121, 8835 (1999). doi:10.1021/ja991400t

17. C. Y. Chen, H. X. Li and M. E. Davis, Micropor. Mater. 2, 17 (1993). doi:10.1016/0927-6513(93)80058-3

18. V. Parvulescu, C. Anastasescu and B. L. Su, J. Mol. Catal. A: Chem 198, 249 (2003). doi:10.1016/S1381-1169(02) $\underline{00694-5}$ 
19. T. Ristoiu, E. Culea and I. Bratu, Mater. Lett. 41, 135 (1999). doi:10.1016/S0167-577X(99)00119-6

20. J. Kliava, I. S. Edelman, A. M. Potseluyko, E. A. Petrakovskaja, R. Berger, I. Bruckental, Y. Yeshurun, A. V. Malakhovskii and T. V. Zarubina, J. Phys. Condens. Matter. 15, 6671 (2003). doi:10.1088/0953-8984/15/40/ $\underline{005}$

21. W. Z. Li, J. G. Wen and Z. F. Ren, Appl. Phys. A: Mater. Sci. Process. 74, 397 (2002). doi:10.1007/s003390201284

22. M. J. Bronikowski, Carbon 44, 2822 (2006). doi:10.1016/ j.carbon.2006.03.022

23. G. Hummer, J. C. Rasalah and J. P. Noworyta, Nature 414, 188 (2001). doi: $10.1038 / 35102535$

24. C. Dellago, M. M. Naor and G. Hummer, Phys. Rev. Lett. 90, 105902 (2003). doi:10.1103/PhysRevLett.90.105902

25. R. D. Bolskar, A. F. Benedetto, L. O. Husebo, R. E. Price, E. F. Jackson, S. Wallace, L. J. Wilson and J. Michael Alford, J. Am. Chem. Soc. 125, 5471 (2003). doi:10.1021/ ja0340984

26. A. Thess, R. Lee, P. Nikolaev, H. Dai, P. Petit, J. Robert, C. $\mathrm{Xu}$, Y. H. Lee, S. G. Kim, A. G. Rinzler, D. T. Colbert, G. E. Scuseria, D. Tománek, J. E. Fisher and R. E. Smalley,
Science 273, 483 (1996). doi:10.1126/science.273. 5274.483

27. N. Das, A. Dalai, J. S. S. Mohammadzadeh and J. Adjaye, Carbon 44, 2236 (2006). doi:10.1016/j.carbon.2006. $\underline{02.040}$

28. D. K. Smith, D. C. Lee and B. A. Korgel, Chem. Mater. 18, 3356 (2006). doi:10.1021/cm060589m

29. X. C. Wu, Y. R. Yao, Y. N. Lu, L. Dong and Z. Hu, Diamond. Relat. Mater. 15, 164 (2006). doi:10.1016/ j.diamond.2005.09.018

30. H. Q. Zhao, C. N. He, J. Ding, T. C. Zou, Z. J. Qiao, C. S. Shi, X. W. Du, J. J. Li and Y. D. Li, J. Alloys. Compd. 428, 79 (2007). doi:10.1016/j.jallcom.2006.03.067

31. A. C. Dupuis, Prog. Mater. Sci. 50, 929 (2005). doi:10.1016/j.pmatsci.2005.04.003

32. J. M. Jehng, W. C. Tung and C. H. Kuo, J. Porous. Mater. 15 (2008) 43. doi:10.1007/s10934-006-9050-X

33. M. Sveningsson, R.E. Morjan, O.A. Nerushev, Y. Sato, J. Backstrom, E. E. B. Camphell and F. Rohmund, Appl. Phys. A 73, 409 (2001). doi:10.1007/s003390100923

34. 3K. Kwok and W. K. S. Chiu, Carbon 43, 437 (2005). doi:10.1016/j.carbon.2004.10.005 